\title{
Remaining challenges in Tanzania's efforts to eliminate iodine deficiency
}

\author{
Vincent D Assey ${ }^{1,2, *}$, Celestin Mgoba ${ }^{1}$, Nicholaus Mlingi ${ }^{1}$, Alfred Sanga ${ }^{1}$, \\ Godwin D Ndossi ${ }^{1}$, Ted Greiner ${ }^{2} \dagger$ and Stefan Peterson ${ }^{3,4}$ \\ 'Tanzania Food and Nutrition Centre, PO Box 977, Dar-Es-Salaam, Tanzania: ${ }^{2}$ Department of Women's and \\ Children's Health, Uppsala University, Uppsala, Sweden: ${ }^{3}$ Department of Public Health Sciences, International \\ Health, Karolinska Institute (IHCAR), Stockholm, Sweden: ${ }^{4}$ Institute of Public Health, Makerere University, Kampala, \\ Uganda
}

Submitted 28 February 2006: Accepted 21 November 2006: First published online 22 February 2007

\begin{abstract}
Objective: To determine iodine levels in salt and iodine deficiency prevalence in school-aged children in 16 districts in Tanzania with previous severe iodine deficiency. Design: A cross-sectional study in schoolchildren. Systematic probability sampling was used to select schools and subjects for goitre assessment and urinary iodine determination.

Setting: Sixteen districts randomly selected from the 27 categorised as severely iodinedeficient in Tanzania.

Subjects: The study population was primary-school children aged 6-18 years who were examined for goitre prevalence and urinary iodine concentration (UIC). Salt samples from schoolchildren's homes and from shops were tested for iodine content. Results: The study revealed that $83.3 \%$ of households $(n=21160)$ in the surveyed districts used iodised salt. Also, $94 \%$ of sampled shops $(n=397)$ sold iodised salt, with a median iodine level of $37.0 \mathrm{ppm}$ (range $4.2-240 \mathrm{ppm}$ ). Median UIC in 2089 schoolchildren was $235.0 \mu \mathrm{gl}^{-1}$ and $9.3 \%$ had UIC values below $50 \mu \mathrm{gl}^{-1}$. The overall unweighted mean visible and total goitre prevalence was $6.7 \%$ and $24.3 \%$, respectively $(n=16222)$. The age group $6-12$ years had the lowest goitre prevalence (3.6\% visible and $18.0 \%$ total goitre, $n=7147)$. The total goitre prevalence had decreased significantly in all districts from an unweighted mean of $65.4 \%$ in the 1980 s to $24.3 \%$ in $1999(P<0.05)$. We believe this difference was also biologically significant.

Conclusion: These findings indicate that iodine deficiency is largely eliminated in the 16 districts categorised as severely iodine-deficient in Tanzania, and that the iodine content of salt purchased from shops is highly variable.
\end{abstract}

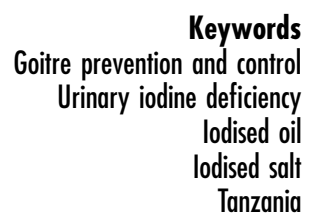

Iodine deficiency is the leading cause of preventable mental retardation. It is estimated that globally 1.6 billion people are at risk of iodine-deficiency disorders (IDD), 760 million people have goitre, 43 million suffer from brain damage and 11 million have overt cretinism ${ }^{1}$. Yet iodine deficiency is fully preventable through supplementation or fortification, usually of salt.

In Tanzania, the presence of IDD was recognised in $1963^{2}$, and between 1980 and 1990 a series of district goitre surveys was conducted to establish the magnitude of the problem. These surveys revealed that an estimated $41 \%$ of the population lived in iodine-deficient areas and were therefore at risk, while $25 \%$ suffered from IDD. This included an estimated 5.6 million people with goitre, 450000 cretinoids and 160000 cretins $^{3}$. In the mid 1980s Tanzania began to

†Currently Senior Nutritionist, PATH, Washington, DC, USA. distribute iodised oil capsules (IOCs) in severely deficient districts as an interim measure, and simultaneously initiated the process of universal iodisation of salt as the permanent strategy, aiming to eliminate IDD by the year $2000^{4}$.

Starting in 1986 IOCs were distributed to the 27 districts most severely affected by IDD, i.e. those with a median urinary iodine concentration (UIC) $\leq 20 \mu \mathrm{gl}^{-1}$, visible goitre $(3+2+1 b)$ prevalence $\geq 10 \%$ or total goitre prevalence $\geq 30 \%{ }^{4}$. By 1998, more than 16 million capsules had been distributed to everyone possible aged $1-45$ years in eligible districts. The mean coverage of 57 rounds of IOC distribution campaigns in the 27 districts from 1986 to 1994 was 64\% (range 24-96\%). Capsule distribution was gradually phased out completely in $1996^{5}$ as salt iodisation was satisfactorily established in each district.

The United Nations Children's Fund (UNICEF) spearheaded the procurement and installation of iodation 
machines of varying iodation capacities ranging from 0.5 to 16 tons per hour. Other inputs supported were potassium iodate, packaging materials and test kits for monitoring salt at production, distribution and consumption levels ${ }^{4}$. A process monitoring system for iodised salt was established from household to national levels. By early 1999, an average of $68 \%$ of rural households and $87 \%$ of urban households in mainland Tanzania had access to iodised salt ${ }^{6}$.

The present cross-sectional study was carried out in 1999 in populations living in known IDD-endemic districts. The objective was to determine the iodine status of the previous severely iodine-deficient population.

\section{Methods}

\section{Study areas, population and sampling}

The present study was conducted in 16 out of the 27 districts that were identified previously as the most severe IDD-endemic districts ${ }^{4}$. These districts are located in nine of the 21 administrative regions of Tanzania mainland. For all regions in which only one district was severely affected, the district was chosen directly for the survey. In regions with more than one affected district, all districts were listed and two or three districts per region were randomly selected by a lottery procedure. Selection of schools within a district was based on three geographical strata, i.e. highland, lowland and township, a criterion that was also used in the baseline survey ${ }^{3}$. Ten schools in each district, i.e. four from highland, four in lowland and two in a township, were selected. A total of 160 schools were selected. However, nine schools (all in different districts and three in each of the geographical strata) could not be reached because of bad roads and heavy rains, and were excluded from the survey.

The study population was primary-school children aged 6-18 years who attended school on the day of the survey. Schoolchildren are commonly used for goitre surveys because of their easy accessibility and their relative suitability in representing the population as a whole ${ }^{1}$.

\section{Salt samples for iodine content}

Salt samples for iodine analysis were collected from households and in retail/wholesale shops. One child from every household brought a teaspoonful of salt wrapped in a dry paper, which was tested for iodine content using a rapid field-test kit (MBI KITS). This is a semi-quantitative method which can detect $\geq 15$ ppm of iodine in salt.

Similarly, a convenience sample of salt brands from shops in the surveyed area was also tested for iodine. Among the salt samples from the shops that tested positive for iodine using the test kit, a convenience sub-sample of five to 10 samples per district was collected for validation of iodine content using the titration method, which has a lower detection threshold of $<1.0 \mathrm{ppm}$ iodine and precision (coefficient of variation, CV) of $<15 \%{ }^{7}$.
UIC

For determination of UIC, a sub-sample of 15 children per school was selected through systematic sampling (after palpation of goitre) to give a urine sample ${ }^{1}$. On average 150 urine samples were collected per district, and each child gave $10-15 \mathrm{ml}$ of urine in a $20 \mathrm{ml}$ tightly closed glass bottle. Analysis was done at the Tanzania Food and Nutrition Centre (TFNC) laboratories using the ammonium persulfate digestion method ${ }^{8}$. The accuracy of the assay method was measured using reference quality control specimens supplied by the Centers for Disease Control and Prevention (CDC); it reached a precision of $\mathrm{CV}<8 \%$, meeting the Division of Laboratory Sciences-CDC's desirable threshold of $\mathrm{CV}<10 \%{ }^{9,10}$.

\section{Goitre prevalence}

Children aged 6-18 years from 151 schools covered were selected using a systematic sampling procedure with all classes proportionately represented. In each school 120 children were sampled for goitre assessment, making an expected grand total of 18120 children. However, due to poor attendance in some schools, only 16222 schoolchildren or $89.5 \%$ of the expected sample size was achieved. The 1960 criteria for goitre classification of the World Health Organization (WHO) ${ }^{11}$ were used to allow comparison with goitre results obtained in the 1980s by the same method $^{3}$, for reasons previously reported ${ }^{12}$. Goitres were graded as $0,1 \mathrm{a}, 1 \mathrm{~b}, 2$ or 3 by two experienced staff who trained on the goitre palpation and grading procedure according to Perez et al. ${ }^{11}$.

\section{Ethics and consent}

The study proposal was approved by the TFNC's Committee on Research and Ethics. Two of the authors participated in executing the study, where they explained the purpose and requirements of the study to the schoolchildren, primary-school teachers and community members. Only those children who gave verbal informed consent participated in the study.

\section{Data processing and analysis}

Data were entered into Epi-Info version 6.02 (CDC/WHO). Entries were validated through running of frequencies and cross-tabulations, and errors rectified against original data forms. Data analysis was done using SPSS version 9.0 (SPSS Inc.) to generate frequencies and proportions for categorical data, and means and medians for continuous data. The non-parametric Mann-Whitney $U$-test was used to compare goitre prevalences in the 1980s with those in 1999. Goitre grades were summed up and categorised as visible goitre prevalence (grades $2+3 / n$ ) and total goitre prevalence (grades $1 \mathrm{a}+1 \mathrm{~b}+2+3 / n)$. $P$-values below 0.05 were considered statistically significant. 


\section{Results}

\section{Use of iodised salt}

Sixty-three per cent of household salt samples provided by the schoolchildren $(n=21160)$ were crushed/fine. The crushed/fine salt found in most shops was packaged in 500-1000 g plastic packets, while raw coarse salt in $50 \mathrm{~kg}$ burlap bags was sold loose from open containers at retail shops and in markets.

Out of 21160 household salt samples, 83\% tested positive, indicating that they had $\geq 15 \mathrm{ppm}$ of iodine. In seven out of the 16 districts $>90 \%$ of the household salt samples were iodised, indicating adequacy ${ }^{1}$, while the proportion of iodised salt in the household samples from the remaining nine districts ranged from 53 to $83 \%$ (Table 1).

In wholesale/retail shops, 94\% of the 397 salt samples tested using test kits had iodine $\geq 15 \mathrm{ppm}$. This proportion would be considered adequate according to the WHO criterion for iodised salt sold in shops at district level ${ }^{1}$.

The median iodine concentration by titration from a sub-sample of 146 out of 397 salt samples in shops, previously tested using test kits, was 37.0 ppm (range 4.2$240 \mathrm{ppm}$ ) and mean was $46.1 \mathrm{ppm}$ iodine. Nearly half of the samples were in the acceptable range (Table 2). In 49\% of samples, iodine was below the government recommended level of $37.5 \mathrm{ppm}^{14}$. Only $4.8 \%$ had excessive levels ( $>100$ ppm iodine).

\section{$\boldsymbol{U I C}$}

Table 1 shows UIC values in 2089 urine samples collected and analysed from primary-school children in 16 districts. The overall median UIC value of $235 \mu \mathrm{gl}^{-1}$ indicates adequate iodine intake (median IUC $\geq 100 \mu \mathrm{gl}^{-1}$ is recommended by WHO for adequacy). However, four districts had low-to-borderline median UIC values: Songea rural (88 $\left.\mu \mathrm{gl}^{-1}\right)$, Ludewa $\left(92 \mu \mathrm{gl}^{-1}\right)$, Mufindi $\left(92 \mu \mathrm{gl}^{-1}\right)$ and Ulanga $\left(70 \mu \mathrm{gl}^{-1}\right)$.

Among the sampled individuals only 9.3\% had UIC $<50 \mu \mathrm{gl}^{-1}$; this is far below the $20 \%$ cut-off point required by WHO for declaring IDD elimination ${ }^{1}$. Meanwhile, $32.2 \%$ and $24.0 \%$ of the individuals had UIC of $200-$ $500 \mu \mathrm{gl}^{-1}$ and $>500 \mu \mathrm{gl}^{-1}$, respectively (Table 3 ).

\section{Prevalence of goitre}

Figure 1 compares total goitre prevalence between the baseline goitre surveys in the 1980s and the present survey in 1999 for the 16 districts. The unweighted mean total goitre prevalence in the 16 districts was $24.3 \%$, range $4.1-49.4 \%$ (Table 1). These results indicate a statistically significant decrease compared with the unweighted total goitre prevalence in the 1980s of $65.4 \%$ (Fig. $1, P<0.05$ ). Such a large difference is also certainly of biological and public health significance.

The total goitre prevalence was $18.0 \%$ in children aged 612 years ( $n=7147), 28.3 \%$ in $13-15$-year-olds ( $n=7041$ ) and $26.7 \%$ in $16-18$-year-olds $(n=2034)$. Visible goitre alone was $<10 \%$ in all age groups (range 3.6-8.6\%), with an unweighted mean of $6.7 \%$, compared with $11 \%$ in the baseline studies ${ }^{4}$, representing a statistically significant decrease $(P<0.05)$ in visible goitre prevalence.

\section{Discussion}

This study suggests that iodine prophylaxis consistently pursued from the mid 1980s to 1999 improved iodine

Table 1 Proportion of households and shops found with $\geq 15 \mathrm{ppm}$ iodine in salt, median urinary iodine concentration $(\mathrm{UIC})$ and prevalence of goitre in schoolchildren by district

\begin{tabular}{|c|c|c|c|c|c|c|c|c|c|}
\hline \multirow[b]{2}{*}{ District } & \multicolumn{2}{|c|}{$\begin{array}{c}\text { Salt samples } \\
\text { with iodine } \\
\geq 15 \mathrm{ppm} \text { at } \\
\text { household } \\
\text { level }\end{array}$} & \multicolumn{2}{|c|}{$\begin{array}{l}\text { Salt samples } \\
\text { with iodine } \\
\geq 15 \mathrm{ppm} \\
\text { from shops }\end{array}$} & \multicolumn{2}{|c|}{$\begin{array}{c}\text { Median } \\
\text { UIC in schoolchildren }\end{array}$} & \multicolumn{3}{|c|}{$\begin{array}{c}\text { Goitre prevalence } \\
\text { in schoolchildren (\%) }\end{array}$} \\
\hline & $n$ & $\%$ & $n$ & $\%$ & $n$ & UIC $\left(\mu g I^{-1}\right)$ & $n$ & VG & TG \\
\hline Arumeru & 2453 & 92.4 & 27 & 96.3 & 168 & 327.8 & 1305 & 6.6 & 34.7 \\
\hline Rombo & 1605 & 97.2 & 45 & 100.0 & 114 & 452.0 & 1298 & 0.7 & 14.9 \\
\hline Mpwapwa & 1039 & 62.1 & 23 & 78.3 & 55 & 173.2 & 1285 & 0.7 & 6.4 \\
\hline Ulanga & 494 & 61.9 & 34 & 85.3 & 67 & 69.8 & 909 & 0.0 & 12.4 \\
\hline Mbeya rural & 1603 & 97.8 & 31 & 96.8 & 149 & 425.4 & 969 & 17.9 & 46.5 \\
\hline Kyela & 1439 & 92.7 & 16 & 100.0 & 149 & 416.0 & 1027 & 0.3 & 4.1 \\
\hline Mbozi & 2374 & 91.2 & 15 & 93.3 & 149 & 339.0 & 1230 & 1.5 & 10.2 \\
\hline Mufindi & 1261 & 77.8 & 21 & 95.2 & 150 & 92.4 & 989 & 8.3 & 23.1 \\
\hline Ludewa & 705 & 76.3 & 19 & 78.9 & 148 & 92.0 & 862 & 8.6 & 29.0 \\
\hline Songea rural & 1384 & 70.5 & 7 & 100.0 & 149 & 88.0 & 993 & 6.4 & 23.7 \\
\hline Sumbawanga & 1102 & 64.3 & 10 & 100.0 & 74 & 194.0 & 480 & 1.0 & 9.6 \\
\hline Mpanda & 1111 & 52.9 & 19 & 94.7 & 165 & 350.0 & 1228 & 1.3 & 9.0 \\
\hline Biharamulo & 1080 & 83.1 & 17 & 82.4 & 141 & 126.0 & 966 & 7.2 & 34.3 \\
\hline Ngara & 723 & 94.2 & 29 & 96.6 & 134 & 395.0 & 799 & 17.6 & 49.4 \\
\hline Kibondo & 1030 & 96.8 & 33 & 100.0 & 136 & 283.0 & 910 & 14.2 & 41.0 \\
\hline Kigoma & 1757 & 80.4 & 51 & 96.1 & 141 & 266.0 & 972 & 14.2 & 40.3 \\
\hline Total & 21160 & 83.3 & 397 & 93.7 & 2089 & 235.0 & 16222 & 6.7 & 24.3 \\
\hline
\end{tabular}

VG - visible goitre (grades $2+3$ ), in this survey no goitre grade 3 was found; $T G-$ total goitre $(1 a+1 b+V G)$ 
Table 2 Distribution of titrated iodine levels in salt samples from shops by category

\begin{tabular}{lrrl}
\hline & \multicolumn{2}{c}{$\begin{array}{c}\text { Salt samples } \\
\text { analysed } \\
\text { by titration } \\
(N=146)\end{array}$} & \\
\cline { 2 - 3 } $\begin{array}{l}\text { Range of iodine } \\
\text { levels }(\mathrm{ppm})\end{array}$ & $n$ & $\%$ & \\
\hline$>100.0$ & 7 & 4.8 & $\begin{array}{l}\text { Public health } \\
\text { significance }\end{array}$ \\
$37.5-100.0$ & 68 & 46.6 & Over-iodation \\
$18.0-37.4$ & 26 & 17.8 & Acceptable \\
$<18.0$ & 45 & 30.8 & Un \\
\hline
\end{tabular}

status, probably by preventing the consequences of iodine deficiency in severely goitre-endemic districts in Tanzania $^{1,4}$. The availability of iodised salt at household level increased dramatically and this decreased goitre prevalence, similar to findings reported in other areas ${ }^{15-17}$. This concurs with the recommendation that salt is the ideal vehicle to deliver iodine to all individuals irrespective of socio-economic status ${ }^{18,19}$. However, several challenges remain before Tanzania can completely eliminate IDD.

\section{Availability of iodised salt}

The salt regulations in Tanzania require that all salt meant for human consumption be iodated at $75-100 \mathrm{ppm}$ at factory level and should not contain $<37.5 \mathrm{ppm}$ iodine at its point of sale ${ }^{14}$. The presence of salt regulations linked to relevant interventions appears to have worked for Tanzania, but the proportion of households in goitreendemic districts with access to iodised salt (83\%) still falls short of the $90 \%$ criterion of adequacy recommended by $\mathrm{WHO}^{1}$. Salt with an iodine level of 10 to $<15 \mathrm{ppm}$ may not be detected by the test kits, but if available constantly it will likely prevent occurrence of goitre in the absence of goitrogens.

Although the median and mean iodine content at retail level (37.0 and $46.1 \mathrm{ppm}$, respectively) was close to complying with Tanzanian standards, the range was wide (4.2-240 ppm) and half the retail samples did not comply. This could be due to inadequate salt iodation, poor handling and storage during transportation, or marketing processes before consumption. The uncontrolled traditional iodation technologies used in some salt

Table 3 Urinary iodine concentration (UIC) by category in children living in goitre-endemic districts in Tanzania

\begin{tabular}{lrr}
\hline & \multicolumn{2}{c}{$\begin{array}{c}\text { Frequency } \\
(N=2089)\end{array}$} \\
\cline { 2 - 3 } UIC by category $\left(\mu \mathrm{gI}^{-1}\right)$ & $n$ & $\%$ \\
\hline$<20$ (severe) & 28 & 1.3 \\
$20-49$ (moderate) & 167 & 8.0 \\
$50-99$ (mild) & 291 & 13.9 \\
$100-199$ (optimal) & 430 & 20.6 \\
$200-500$ (excessive) & 672 & 32.2 \\
$>500$ (seriously excessive) & 501 & 24.0 \\
\hline
\end{tabular}

$\square$ Before intervention $\square$ After intervention

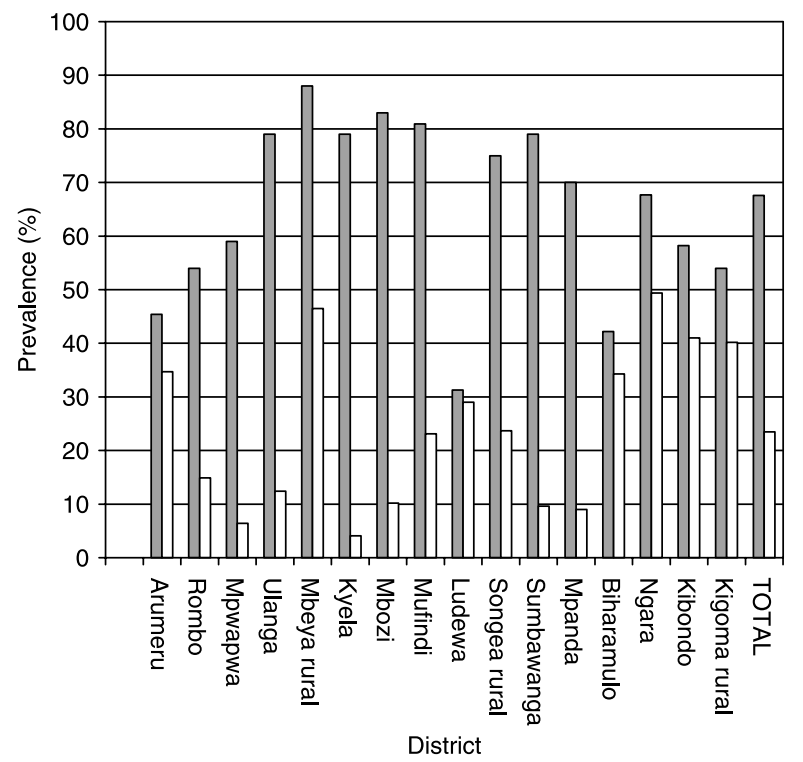

Fig. 1 Total goitre prevalence before (1980s) and after intervention (1999) in 16 high-prevalence districts in Tanzania

production sites is likely to lead to a lack of homogeneity in salt-iodine mixing ${ }^{13}$. Some of the salt iodation and storage processes probably are inadequate to control iodine losses. This suggests that there is a need to improve iodation and salt storage procedures and to strengthen internal quality assurance ${ }^{13,20}$.

Currently, levels of iodine in salt at household level are on average too low. Yet mean UIC is too high in some districts. One way to deal with these discrepancies would be to improve homogeneity during salt iodation. Continued surveillance is required, as increased use of consumer packaging could eventually require a downward revision of national recommendations for salt iodation levels at production level ${ }^{14}$. Risks of iodineinduced thyrotoxicosis may be substantial in some population groups ${ }^{21}$, and this has received only cursory research attention in Tanzania ${ }^{4}$.

\section{Urinary iodine}

Urinary iodine is considered the most reliable indicator for IDD assessment in populations. The intake of iodine in a population is considered adequate when the median value of UIC is between 100 and $200 \mu \mathrm{gl}^{-1}$, with not more than $20 \%$ of the samples below $50 \mu \mathrm{gl}^{-1}$ (references 1 and 22), which is the criterion met in the districts sampled.

However, $24.0 \%$ of children actually had median UIC $>500 \mu \mathrm{gl}^{-1}$ (Table 3). Urinary iodine $>500 \mu \mathrm{gl}^{-1}$ is regarded as a serious excessive iodine intake, since it has been associated with increased thyroid volume which reflects the adverse effects of excess iodine ${ }^{23}$. This emerging problem of serious excessive iodine intake observed in Tanzania was also recently reported in Lesotho $^{24}$ 
Four districts with median UIC values $<100 \mu \mathrm{gl}^{-1}$ had salt supplied primarily by small-scale producers along the south-eastern coast and central regions of Tanzania, and quality control at the point of iodation for the multitude of small-scale salt producers is inadequate ${ }^{4}$. This suggests that there is a need to have periodic surveys of salt and UIC to monitor actual iodine intake, which then should be adjusted accordingly to ensure a steady median UIC at $100-200 \mu \mathrm{gl}^{-1}$ and low proportions below $50 \mu \mathrm{gl}^{-1}$.

Ulanga is one of the few districts that had successful coverage of IOC distribution ${ }^{4}$ followed by high coverage of availability of iodised salt at household level in the mid 1990s. Sustainable elimination of iodine deficiency needs continuous surveillance to avoid the recurrence of mild iodine deficiency, as recently reported in Tasmania and Morocco $^{25,26}$.

\section{Goitre prevalence}

After more than a decade of intervention, findings in this study showed that the magnitude of the IDD problem in Tanzania has declined from severe to moderate rate according to WHO standards ${ }^{1-4}$. Apparent goitre prevalence has decreased substantially but still remains high in nine districts (Table 1 and Fig. 1). Ludewa district, with the mildest problem at the baseline survey, showed the least improvement.

There was also little reduction of goitre prevalence in the western districts of Biharamulo, Ngara, Kibondo and Kigoma. This could be due to poor availability of iodised salt from the local large-scale Uvinza salt factory after it was closed for a long period. Also, there has been an influx of refugees into western Tanzania from neighbouring countries where iodine interventions have been hindered by long ethnic wars (Burundi, Democratic Republic of Congo and Rwanda). In Tanzania these refugees received iodised salt whether or not they integrated into local communities, but it will take time for the goitres to regress ${ }^{27}$. That this salt is now adequately iodated is indicated by the high UIC values in these districts.

Goitre regression may be delayed in some districts due to low coverage of the IOC supplementation implemented earlier $^{5}$. In other cases IOC distribution may have ended before iodised salt was adequately supplied and consistently available.

Goitre prevalence varied with age; the youngest children, 6-12 years old, had the lowest prevalence. This is likely, in part, a cohort effect and has been found in similar studies in Tiberina valley in Italy $^{28}$ and Lesotho ${ }^{29}$. These younger children were born during the period when IOCs were being widely distributed in these districts $^{5}$. From 1990, salt iodisation gradually started in Tanzania and by 1999 iodised salt was reaching about 77\% of the population ${ }^{6}$, protecting the younger age group against IDD ${ }^{30,31}$. Thyroid size in older children exposed to iodine deficiency in the first years of life might fail to regress completely following consumption of iodised salt, as observed in previous studies ${ }^{32,33}$. This suggests that goitre prevalence may not be the most appropriate indicator to use in short-term evaluations ${ }^{33}$.

The impact (total goitre prevalence declined from $65.4 \%$ in the 1980 s to $24.3 \%$ in 1999) observed in this study is smaller than was seen in Jixian, China, where it was claimed to fall from $65 \%$ to $4 \%$ only four years after introduction of iodised salt ${ }^{32}$. If the results from the four western districts (described above) are left out, the unweighted mean goitre prevalence for the other 12 districts declined from $68.3 \%$ to $18.6 \%$. However, while goitre remains in many areas, we are encouraged by the high urinary iodine levels.

The current iodine status in the vast areas of Tanzania with moderate, mild or no iodine deficiency is not known. Nationwide investigations could assess possible overiodation and its effects in these areas. There may also be small isolated areas of severity not yet adequately reached by iodised salt. This study reflects the situation in schoolchildren, but other vulnerable groups such as pregnant women and neonates are critical and should also be carefully studied before declaring national elimination of iodine deficiency ${ }^{34}$.

We were unable to survey nine out of the 160 schools selected to be in the second survey. As is the case for any survey repeated after such a long period of time in such a low-income setting, there are methodological problems limiting the accuracy of the findings. Goitre palpation always involves substantial intra- and interpersonal variation among examiners ${ }^{12}$. This study benefited from the fact that much of the palpation was done by the same individuals in both surveys, all of whom were highly skilled and experienced.

The results indicate substantive success in controlling a major public health problem in some of the areas worst affected by IDD in a very low-income country like Tanzania. The district differences we found suggest that the approach of doing national-level studies, as reported by Andersson et al. ${ }^{35}$, may conceal continued iodine deficiency in large segments of the population.

\section{Acknowledgements}

Sources of funding: The work was funded by the Government of Tanzania and UNICEF.

Conflicts of interest: None declared.

Authorship contributions: V.D.A. was the principal author responsible for study design, conducting the field research upon which this paper was based and writing the manuscript. C.M. contributed in the statistical analyses of study data and provided scientific comments during manuscript writing. N.M. contributed in the interpretation of laboratory data and in writing the manuscript. A.S. contributed in early planning of the survey, examined children for goitre and provided comments on the manuscript. G.D.N. participated in study design and 
critical review of the manuscript before submission. T.G. provided intellectual input and contributed to writing the manuscript. S.P. contributed to the study design and provided intellectual input in writing the manuscript.

Acknowledgments: We would like to express our gratitude to all those who in one way or another contributed to the accomplishment of the study. We are also grateful to the Ministry of Education and Culture in Tanzania for the cooperation and assistance extended to the survey team, especially from the District Education Officers, primary-school teachers, school committees and children who participated in this survey. Special thanks to TFNC staff who contributed in survey planning, fieldwork and carrying out laboratory analyses. The authors wish to acknowledge to the support from the Government of Tanzania and UNICEF for funding the study.

\section{References}

1 World Health Organization (WHO)/United Nations Children's Fund/International Council for Control of Iodine Deficiency Disorders. Assessment of Iodine Deficiency Disorders and Monitoring their Elimination. A Guide for Programme Managers. WHO/NHD/01.1. Geneva: WHO, 2001; 1-107.

2 Latham MC. A goitre survey in Ukinga, Tanzania (formerly Tanganyika). Transactions of the Royal Society of Tropical Medicine and Hygiene 1965; 59(3): 342-8.

3 van de Haar F, Kavishe P, Medhin MG. Public health importance of IDD in Tanzania. Central African Journal of Medicine 1988; 34: 60-5.

4 Kavishe F, Mushi S. Nutrition-relevant Actions in Tanzania. A Case Study for the XV Congress of the International Union of Nutrition Sciences. Adelaide: United Nations Administrative Committee on Coordination, Sub-committee on Nutrition, 1993.

5 Peterson S, Assey V, Forsberg BC, Greiner T, Kavishe FP, Mduma B, et al. Coverage and cost of iodized oil capsule distribution in Tanzania. Health Policy Planning 1999; 14(4): 390-9.

6 Government of Tanzania. Tanzania Reproductive and Child Health Surveys (TRCHS). Calverton, MD: Tanzania Bureau of Statistics/Macro International, 1999.

7 United Nations Children's Fund/International Council for Control of Iodine Deficiency Disorders/Program Against Micronutrient Malnutrition/World Health Organization (WHO)/Micronutrient Initiative. Monitoring Universal Salt Iodization Programmes. Ottawa: WHO, 1995.

8 Pino S, Fang SL, Braverman LE. Ammonium persulfate: a safe alternative oxidizing reagent for measuring urinary iodine. Clinical Chemistry 1996; 42(2): 239-43.

9 Haldimann M, Zimmerli B, Als C, Gerber H. Direct determination of urinary iodine by inductively coupled plasma mass spectrometry using isotope dilution with iodine-129. Clinical Chemistry 1998; 44(4): 817-24.

10 Centers for Disease Control and Prevention (CDC). Ensuring the Quality of Urinary Iodine Procedures (EQUIP). Atlanta, GA: CDC, 2000.

11 Perez C, Scrimshaw NW, Munoz JA. Technique of endemic goitre surveys. In: Endemic Goitre. Geneva: World Health Organization, 1960; 369-83.

12 Peterson S, Sanga A, Eklöf H, Bunga B, Taube A, GebreMedhin $\mathrm{M}$, et al. Classification of thyroid size by palpation and ultrasonography in field surveys. Lancet 2000; 355(9198): 106-10.
13 Chauhan SA, Bhatt AM, Bhatt MP, Majeethia KM. Stability of iodised salt with respect to iodine content. Research and Industry 1992; 37: 38-41.

14 United Republic of Tanzania. The Food (Control of Quality) Act, 1978; The Mining Act, 1979; Regulations made under Section 16(1) and (2), The Food (Iodated Salt) Regulation, 1992; The Mining (Salt Production and Iodation) Regulations, 1994

15 l'Ons A, Jooste PL, Weight MJ, Huskisson J. A field clinical trial of the short term effects of iodised salt on iodine status of rural primary school children. South African Journal of Clinical Nutrition 2000; 90: 30-3.

16 Jooste PL, Weight MJ, Lombard CJ. Short-term effectiveness of mandatory iodization of table salt, at an elevated iodine concentration, on the iodine and goiter status of schoolchildren with endemic goiter. American Journal of Clinical Nutrition 2000; 71(1): 75-80.

17 Salarkia N, Hedayati M, Mirmiran P, Kimiagar M, Azizi F. Evaluation of the impact of an iodine supplementation programme on severely iodine-deficient schoolchildren with hypothyroidism. Public Health Nutrition 2003; 6(6): 529-33.

18 World Health Organization (WHO)/United Nations Children's Fund/International Council for Control of Iodine Deficiency Disorders. Recommended Iodine Levels in Salt and Guidelines for Monitoring Adequacy and Effectiveness. WHO/NUT/96.13. Geneva: WHO, 1996.

19 Mannar V, Dunn J. Salt Iodization for Elimination of Iodine Deficiency. Wageningen: International Council for Control of Iodine Deficiency Disorders, 1995.

20 Dunn J, van de Haar F. A Practical Guide to the Correction of Iodine Deficiency. Technical Manual No. 3. Wageningen: International Council for Control of Iodine Deficiency Disorders/World Health Organization/United Nations Children's Fund, 1990.

21 Delange F, de Benoist B, Alnwick D. Risks of iodine-induced hyperthyroidism following correction of iodine deficiency by iodized salt. Thyroid 1999; 9(6): 545-56.

22 Delange F, de Benoist B, Burgi H. Determining median urinary iodine concentration that indicates adequate iodine intake at population level. Bulletin of the World Health Organization 2002; 80(8): 633-6.

23 Zimmerman MB, Ito Y, Hess SY, Fujieda K, Molinari L. High thyroid in children with excess dietary iodine intakes. American Journal of Clinical Nutrition 2005; 81(4): 840-4 Erratum in American Journal of Clinical Nutrition 2005; 82(1): 203.

24 Sebotsa ML, Dannhauser A, Jooste PL, Joubert G. Iodine status as determined by urinary iodine excretion in Lesotho two years after introducing legislation on universal salt iodation. Nutrition 2005; 21(1): 20-4.

25 Guttikonda K, Burgess JR, Hynes K, Boyages S, Byth K, Parameswaran V. Recurrent iodine deficiency in Tasmania: a salutary lesson in sustainable iodine prophylaxis and its monitoring. Journal of Clinical Endocrinology and Metabolism 2002; 87(6): 2809-15.

26 Zimmerman MB, Wegmuller R, Zeder C, Torresani T, Chaouki N. Rapid relapse of thyroid dysfunction and goiter in schoolage children after discontinuation of salt iodization. American Journal of Clinical Nutrition 2004; 79(4): 642-5.

27 Peterson S, Assey V, Dalenbring M, Lorri W, Gebre-Medhin M. Adequate iodine status in a Rwandan refugee population despite residence in an iodine deficient area of Tanzania. Svenska Läkaresällskapets handlingar Hygiea 1995, 380.

28 Aghini-Lombardi F, Antonangeli L, Pinchera A, Leoli F, Rago T, Bartolomei AM, et al. Effect of iodized salt on thyroid volume of children living in an area previously characterized by moderate iodine deficiency. Journal of Clinical Endocrinology and Metabolism 1987; 82(4): 1136-9.

29 Sebotsa M, Dannhauser A, Jooste PL, Joubert G. Prevalence and goitre and urinary iodine status of primary-school 
children in Lesotho. Bulletin of the World Health Organization 2003; 81(1): 28-34.

30 Pharaoh PO, Connolly KJ. A controlled trial of iodinated oil for the prevention of endemic cretinism: a long-term followup. International Journal of Epidemiology 1987; 16(1): $68-73$.

31 Pichard E, Soula G, Fisch A, Rhaly AA, Diarra M, Sebbaq R, et al. Prevention of iodine deficiency disorders in children in the rural African zone. Annals of Paediatrics (Paris) 1992; 39(2): 71-8.

32 Jianqun L, Quingyu H, Xin W. Studies of the effect of salt iodization in the village of Jiaxin - China. IDD Newsletter 1987; 3: 4-5.
33 Zhao JZQ, Shang L, Chen Z, Hu X. Effects of three different iodine interventions on the speed of normalisation of enlarged thyroid gland due to iodine deficiency. Zhonghua Liuxingbingxue Zazhi 2002; 24(4): 254-7.

34 Sundqvist J, Wijetunga M, Assey V, Gebre-Medhin M, Peterson S. Salt iodation and risk of neonatal brain damage. Lancet 1998; 352(9121): 34-5.

35 Andersson M, Takkouche B, Egli I, Allen HE, de Benoist B. Current global iodine status and progress over the last decade towards elimination on iodine deficiency. Bulletin of the World Health Organization 2005; 83(7): 518-25. 